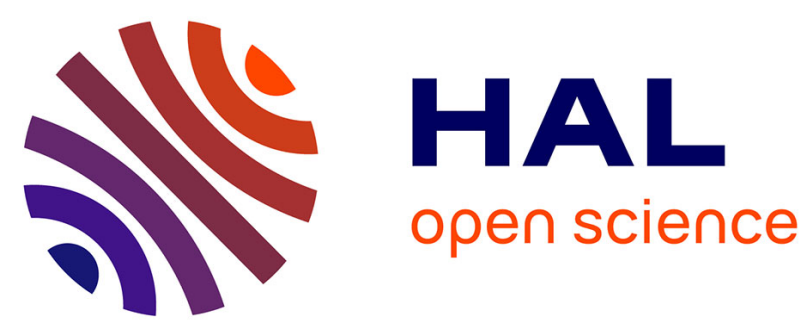

\title{
Key issues in phage therapy: a report of a dedicated workshop at the Viruses of Microbes II meeting.
}

Isabelle Huys, Mario Vaneechoutte, Gilbert Verbeken, Laurent Debarbieux

\section{To cite this version:}

Isabelle Huys, Mario Vaneechoutte, Gilbert Verbeken, Laurent Debarbieux. Key issues in phage therapy: a report of a dedicated workshop at the Viruses of Microbes II meeting.. Research in Microbiology, 2013, 164 (7), pp.806-10. 10.1016/j.resmic.2013.03.020 . pasteur-01539091

HAL Id: pasteur-01539091

https://hal-pasteur.archives-ouvertes.fr/pasteur-01539091

Submitted on 17 Jul 2018

HAL is a multi-disciplinary open access archive for the deposit and dissemination of scientific research documents, whether they are published or not. The documents may come from teaching and research institutions in France or abroad, or from public or private research centers.
L'archive ouverte pluridisciplinaire HAL, est destinée au dépôt et à la diffusion de documents scientifiques de niveau recherche, publiés ou non, émanant des établissements d'enseignement et de recherche français ou étrangers, des laboratoires publics ou privés. 


\section{Key issues in phage therapy: a report of a dedicated workshop at the viruses of microbes II meeting}

\section{Summary}

A workshop addressing key issues in phage therapy was organized by the non-profit organization P.H.A.G.E. during the Viruses of Microbes II meeting, held in July 2012 in the Royal Military Academy, Brussels, Belgium. This report summarizes the major points that were addressed by the panel of experts from the academic, public, private and legal domains.

\section{The experts}

During the Viruses of Microbes II meeting, held in July 2012 at the Royal Military Academy in Brussels, Belgium, a workshop was dedicated to the clinical and regulatory barriers and opportunities of the development of phage therapy in Europe. A panel, chaired by Isabelle Huys (Univ. Leuven, Belgium) and Martin Zizi (Free Univ. Brussels, Belgium, and president of P.H.A.G.E.), included experts from diverse domains: Jacques Scheres, board member of the European Centers for Disease Control (ECDC, Stockholm, Sweden), a leading European authority on the surveillance of bacterial resistance problems and new antibacterial strategies. Jérôme Larché, head of the intensive care unit in Narbonne Hospital (France) and president of the non-profit organization, PHAGESPOIR, who represented the public sector. Harald Brüssow from the Nestlé Research Center, Vers-Chez-Les-Blancs, Switzerland and David Harper from BioControl, AmpliPhiBiosciences (Colworth Science Park, London, UK) who were delegates from private companies. $\mathrm{H}$. Brüssow is involved since years in directing phage research and safety trials (e.g. Brüttin and Brüssow, 2005) for a large multinational company (Nestlé). D. Harper is the founder and scientific officer of the startup which carried out the first phage trials using modern, rigorous, clinical trials standards (Wright et al., 2009). Andrzej Górski from the Hirszfeld Institute of Immunology and Experimental Therapy (Wroclaw, Poland) represented the long-standing 'Eastern Bacteriophage therapy tradition' and is leading translational and fundamental research on phages (Górski et al., 2009, 2012). Angus Buckling from the University of Exeter (UK) has published extensively on the interaction of phages and bacteria to better understand and deal with the problems of emerging bacterial resistance to phages when they are used therapeutically as antibacterial agents (Hall et al., 2012). Gilbert Verbeken (Laboratory of Molecular and Cellular Technology, Burn Wound Center, Queen Astrid Military Hospital, Brussels, Belgium) is a specialist concerned with the numerous regulatory hurdles confronting clinical trials of phage therapy (Verbeken et al., 2007). Isabelle Huys's expertise is in intellectual property (IP) affairs particularly focused in phage therapy.

\section{The need for phage therapy}

The discussion started with what is, without a doubt, considered as one of the most serious problems confronting public health authorities: the emergence of bacterial pathogens that are resistant to the existing antibiotics and the failure to develop new types of antibiotics. There was unanimity that the overuse of antibiotics has to be reduced in order to slow down the emergence of pan-resistant bacterial pathogens and in addition, physicians as well as medical students need to be educated accordingly. However, other antibacterial solutions are urgently needed since some patients are nowadays confronted with the difficulty if not yet impossibility to treat their bacterial infections.

Phage therapy, initiated early in the previous century by Félix D'Herelle at the Institut Pasteur (Paris, France), and almost exclusively expanded post World War II to several Eastern European countries, represents a sustainable solution, as demonstrated by its clinical use especially in Poland and Georgia. In Western Europe, phage therapy does not picture the conventional therapeutic schemes for infectious diseases. Nevertheless, would it be unreasonable to consider unconventional solutions when dealing with therapeutic impasses involving the life and well-being of patients? A reasonable, responsible and appropriate response to that question, proposed along this workshop, was: 'Surely not, if done with moderation and reason, and keeping in consideration that the only objective is the improvement of the patient's condition.'

\section{The eastern legacy}

Phage therapy has been implemented for decennia under the umbrella of the Declaration of Helsinki, a non-binding legal instrument providing for some ethical principles 
regarding human experimentation. A large set of data on phage therapy has via this way partially been published previously (Górski et al., 2009; Weber-Dabrowska et al., 2000). In addition, under the auspices of the UK Global Threat Reduction Program, a literature review and an English translation of some of the past Georgian clinical trials have been published as well (Chanishvili, 2009, 2012).

The question is now whether it would be useful to preserve and exploit such valuable experimental data from the past and how such data could be implemented to serve the community. There was general agreement that preservation of this abundance of data from the East is of real importance and requires for example the creation of a centralized bank, or an online inventory of the various Phage Collections. When possible, associated useful scientific and clinical information should be collected. Such a central facility would enable the community to classify, organize and study those phages and most importantly would increase their availability to be employed for therapeutic use. This would also prevent isolation of related phages again and again.

\section{Assessing phage efficacy}

The ability of phages to act as anti-infectious agents (efficacy) is most probably due to their direct killing action on bacteria. This is most prominent in treatments of acute infections resulting from massive clonal bacterial invasion, as is the case for Escherichia coli enteritis in cattle, while Salmonella and Campylobacter infections, being more dispersed, would be less prone to phage treatments. Complete elimination of the pathogen is however not required, as the reduction of the bacterial load appears sufficient to decrease symptoms, allowing the immune defense to take over. For human treatments, what really matters is the clinical outcome, the favorable clinical progression, not the complete eradication of the harmful bacteria. This was observed in the chronic otitis clinical trials conducted by BioControl, where the symptoms were relieved for several patients despite the persistence of some Pseudomonas aeruginosa (Wright et al., 2009).

Although counterintuitive, there might be good scientific reasons for such observations. Besides a favorable initial strong reduction in bacteria following phage application, the resistant bacterial mutants against the phages that eventually emerge may be less virulent and then less prone to elimination by the immune system. Indeed, this loss of virulence is frequently due to mutations affecting ligands involved in bacterial invasion (adhesins, invasins) or subversion of the immune system (PAMPs). Such ligands exposed to the cell surface are also used by phages as receptors for adsorption and the subsequent infection of their bacterial hosts. In a classical example described 30 years ago, E. coli $\mathrm{K} 1$, a virulent encapsulated strain, acquired resistance during an experimental treatment with phages in animals by becoming K1negative as a consequence of mutations and lost its virulence (Smith and Huggins, 1982).
Another possible explanation of the ability of phages to act as anti-infectious agents, that is not related to their antibacterial activity, might be their immunomodulatory and antiinflammatory properties, which thus far have remained understudied (Górski et al., 2012).

\section{The problem of resistance}

Although bacterial resistance to phage could cause a simultaneous decrease in bacterial virulence (see above), much caution needs to be exerted to avoid the same problems that we now experience with antibiotics. Widespread use of phages for human therapy, extensive prescriptions of phage products and the treatment of livestock could inevitably lead to substantial shedding of these phage strains in the environment and thus could result in increased bacterial resistance to these phages. It will be therefore important, at least during sometime, to keep phage applications on a limited scale, for clearprescribed indications. Education of future medical doctors toward responsible prescription of phages should also be included in the development of phage therapy. Resistance is however from a different kind as with antibiotics. There is the continuously ongoing arms race/competition between bacteria and phages, and specific phages that are able to infect the formerly resistant bacterial strains can be expected to quickly emerge (Pirnay et al., 2012). More experimental evolution studies are however necessary to determine the potential negative evolutionary consequences of unlimited phage therapy. Ideally, environmental microbiology studies could help to address this potential problem before it became a serious concern. Last but certainly not the least aspect of the development of phage therapy comes from the use of phages in combination with conventional antibiotic treatments, as supported by a synergy observed in vitro between some phages and some antibiotics (Comeau et al., 2007). Most likely, some clinical data from Eastern Europe dataset should exist and be used to guide this strategy that has been so far under looked in vivo.

\section{Regulatory hurdles}

Accepting phage therapy as new cure in Western Europe involves crucial legal issues which seem very phage-specific. Therefore, some propose to regulate phage therapy via a separate, eventually new regulatory category that would account for the intrinsic ability of phages to evolve over time, as opposed to traditional antibiotics (Verbeken et al., 2007; Pirnay et al., 2011). The existence of such a specific regulatory category could significantly facilitate clinical studies. There are various examples of existing discrepancies in the ways regulatory authorities treat different classes of products. For example, a separate category has been created to allow the toleration of homeopathic products, because the authorities were confronted with a fait accompli of an enormous variety of products already established in the market. Hence, they were forced to create a separate category to assure at least a bare minimum control of these products. On the other hand, 
some consider phages to be categorized as 'biologics', fitting in the same subcategory than vaccines. This subcategory is clearly defined, in part, as 'aimed at curing diseases with living viruses', a definition which fits phages perfectly well. Moreover, the vaccine subcategory tolerates some modest level of naturally occurring changes of the vaccine products without the necessity of initiating an entirely new regulatory procedure. For example, when protection from a newly arisen variant pathogen is urgently required (as in a flu vaccine), the appropriate modification of the vaccine can be easily and rapidly accommodated by the flexibility of the regulations. Such flexibility would be invaluable for therapeutic phage cocktails, since they will need to be regularly updated because of the emergence of phage resistant bacterial mutants. However, phage cocktails and phage-based products in general may actually require greater compositional flexibility than the once-in-a-year updates that suffices for vaccines. Then the question remains whether regulators would accept to increase further the current flexibility.

An additional difficulty to consider is the standardization of the therapeutic phage-based products. Even a product made from a complete clonal phage population can change within the patient. While this can be seen as the ultimate advantage of phage therapy over treatment with antibiotics, as the phage can coadapt to an evolving pathogen, this intrinsic genetic variability poses serious problems with respect to current policies advocated by the regulatory authorities that place major emphasis on the compositional uniformity of a therapeutic product.

Phage therapy requires the selection and application of phages specifically targeting a particular patient's bacterial strain. In such a setting, it is important to distinguish between two regulatory definitions, namely 'product quality' and 'production quality'. For companies that want to market a well-defined product, regulatory instances require 'product quality'. However, for custom-made products such as, for example, the different combinations of phages that may be required to deal with an emerging bacterial pathogen, it might be better to opt for 'production quality' rather than 'product quality'. Thus, although the product may change slightly, the production procedure would be standardized to ensure uniform high quality of each individual batch.

Another way out of this regulatory conundrum is to get a 'hospital exemption' from the regulatory restrictions in case phage therapy is applied within a hospital under supervision of a medical doctor in a patient-specific setting. This would allow the therapeutic application of phages, in cases of urgent and serious health problems, like the German Shiga-toxin producing EHEC strains that caused 54 deaths in June 2011, and which could not be successfully treated with antibiotics. Such tolerance would be necessary also today to offer a solution for some chronically infected patients for which antibiotics are not sufficient any more.

In addition to regulatory hurdles, issues with respect to IP have withheld companies and other investors from investing into phage therapy thus far. There are several patents (primarily originating from the US) claiming protection for various aspects of phage therapy, ranging from natural phages, to phage cocktails and to various phage methods of treating infectious diseases of bacterial origin. However, the validity and enforceability of these patents are dubious since many of them are overly broad and/or are imprecisely defined. As a consequence, there is a widespread issue of legal uncertainty for companies, hospitals and public institutions involved in the applications of phage therapy.

\section{And then, there is safety}

Despite the sometimes kafkaesque regulations and exorbitant safety concerns about phage therapy, the fact remains that it has been generally proven to be very safe. However, there simply is no way to avoid some safety regulations for phage therapy. Indeed, however strong the claims regarding general safety of phage preparations employed in the Eastern European experience are, from the rigid point of view of the regulatory authorities, they absolutely need to be convinced of the safety of the precise product that will be employed in any future therapy trials. For example, they must be convinced of the absence of any possible harmful contamination or any possible risk coming from the phage itself or its solute. Previous safety data records, no matter how convincing and numerous they may be, do not constitute a credible assurance of the safety of a related new product (or even of a different batch of exactly the same product) used in clinical trials. This is not a specific problem related to phage therapy, even for well-established products in clinical trials (for example, magisterial preparations that have been long employed in a hospital), the regulatory authorities require that investigational medical products documents be filed and that certification be provided that these products are produced under Good Manufacturing Procedures conditions. Although phages seem safe and can cause spectacular improvements in patients in some situations, this therapy still needs to be applied with some caution. In spite of the substantial empirical use in Eastern Europe, the numerous experimental animal studies, the encouraging preclinical studies on ex vivo samples, rigorous scientific evaluation will still be necessary for general clinical use of phage therapy.

\section{High costs, an inescapable major hindrance in the pursuit of clinical trials}

The best way to rigorously evaluate phage therapy is through clinical trials in order to establish proof of principle and to stimulate additional funding. But, in the first place, funding itself is the primary bottleneck for setting up expensive clinical trials. Hence, the current lack of clinical trials on phage therapy indicates a general hesitancy of industry to invest the large sums necessary to confirm phage safety and efficacy. Presumably, and in view of the regulatory and IP hindrances indicated above, the current evaluation of the industry is that it is not worth the large risks for them to do it by themselves. Perhaps with the help of public support they may get involved.

It is actually quite striking that public scientific institutions have begun to promote 'translational' and 'personalized' medicines as a widespread concepts, but that many of the 
creative ideas provided by the publically funded scientists for potentially useful therapeutic agents and therapy strategies are too often put aside when facing regulatory requirements. The huge development cost of such long-term research projects and the inevitable uncertainties presented by the strict regulatory requirements cannot be carried alone by academic institutions, neither industrial startups. In consequence, the notion that the development of phage therapy will be comparatively cheap in comparison to new antibiotic development is probably too simplistic and fundamentally flawed. Considering the cost of production, both strategies are relatively inexpensive but they are also equivalently expensive to be developed for use in clinical trials and to eventually bring into the market, because the costs of overcoming the regulatory restrictions (e.g. number of trials, patients to be included, ...) are essentially the same for both and, indeed, very expensive. Moreover, since a phage preparation may have only a narrow spectrum of sensitive bacterial targets, the return-oninvestment for each preparation often may be too low for any company to justify the risk. As clinical trial costs for phages are at least as high as they are for antibiotics and since the market for each phage product could be intrinsically rather limited in their narrow therapeutic range, the profitability for private phage-producing companies may simply be too modest to provide economic sustainability.

\section{The European authorities}

The lack of implementation of phage therapy presents a real concern and triggers interest at the highest levels in Europe, such as the ECDC which is responsible for the surveillance of infectious diseases. This interest might forecast a significant evolution in Europe's attitude toward phage therapy, which in the past can be fairly described as highly skeptical. The time has now come in Europe, to take phage therapy seriously. Patient groups and medical doctors should be encouraged to exert pressure on the both European institutions and elected political bodies because policy changes are only rarely initiated from above. More often these structures only respond positively and rapidly to initiatives that originate from extramural sources that have wide public support. Since regulators only apply rules, they do not change them, political pressure must be exerted from the bottom to influence the top. This strategy is essentially what is being applied in France by PHAGESPOIR, by actively implicating the patients who would be the potential beneficiaries for phage therapy in the appeals to the regulatory authorities and politicians. The responsibility to move forward and not tolerate the status quo rests not just with the public health authorities and health professionals, but also squarely on the patients. There is also an urgent need for research funding to explore and improve the efficacy of phage therapy and importantly to unambiguously demonstrate its safety.

One could then see explicitly with a video presentation made by His Excellency Mr. Pieter De Crem, Belgian Minister of Defense (http://player.vimeo.com/video/43203048) a glimpse of the involvement of public authorities as a sign that the status quo may not stand any longer.

In conclusion, this workshop was perceived by both the audience and the panel members as a milestone in the development of phage therapy (Brüssow, 2012). The road will certainly not be short, as normal with development of new medical treatments. But it is a road that must be explored and that hopefully can get to its end before an inevitable outbreak of a lethal infectious disease caused by an emergent bacterium, resistant to our existing arsenal of antibiotics, emerges.

\section{Acknowledgment}

We thank the organization team of the meeting VoM II as well as the board of PHAGE more specifically to have organized this workshop. This work was supported with a research community grant (WO.022.09) of the FWO Vlaanderen.

\section{References}

Brüttin, A., Brüssow, H., 2005. Human volunteers receiving Escherichia coli phage T4 orally: a safety test of phage therapy. Antimicrob. Agents Chemother. 49, 2874-2878.

Brüssow, H., 2012. What is needed for phage therapy to become a reality in Western medicine? Virology http://dx.doi.org/10.1016/j.virol.2012.09.015. pii: S0042-6822(12)00456-4

Chanishvili, N., 2009. A Literature Review of the Practical Application of Bacteriophage Research. Eliava Institute of Bacteriophage, Microbiology \& Virology, Tbilisi, Georgia, p. 184.

Chanishvili, N., 2012. Phage therapy - history from Twort and d'Herelle through Soviet experience to current approaches. Adv. Virus Res. 83, 3-40.

Comeau, A.M., Tétart, F., Trojet, S.N., Prère, M.-F., Krisch, H.M., 2007. Phage-antibiotic synergy (PAS): beta-lactam and quinolone antibiotics stimulate virulent phage growth. PLoS One 2 (8), e799.

Górski, A., Miedzybrodzki, R., Borysowski, J., Weber-Dabrowska, B., Lobocka, M., Fortuna, W., Letkiewicz, S., Zimecki, M., Filby, G., 2009. Bacteriophage therapy for the treatment of infections. Curr. Opin. Investig. Drugs 10, 766-774.

Górski, A., Międzybrodzki, R., Borysowski, J., Dąbrowska, K., Wierzbicki, P., Ohams, M., Korczak-Kowalska, G., Olszowska-Zaremba, N., LusiakSzelachowska, M., Kłak, M., Jończyk, E., Kaniuga, E., Gołaś, A., Purchla, S., Weber-Dąbrowska, B., Letkiewicz, S., Fortuna, W., Szufnarowski, K., Pawełczyk, Z., Rogóż, P., Kłosowska, D., 2012. Phage as a modulator of immune responses: practical implications for phage therapy. Adv. Virus Res. 83, 41-71.

Hall, A.R., De Vos, D., Friman, V.P., Pirnay, J.P., Buckling, A., 2012 Jun 1. Effects of sequential and simultaneous application of bacteriophages on populations of Pseudomonas aeruginosa in vitro and in waxmoth larvae. Appl. Environ. Microbiol.. (Epub ahead of print).

PHAGESPOIR. http://phagespoirs.unblog.fr/.

P.H.A.G.E.: Phage for Human Application Group Europe.http://www.p-h-a-ge.org.

Pirnay, J.P., De Vos, D., Verbeken, G., Merabishvili, M., Chanishvili, N., Vaneechoutte, M., Zizi, M., Laire, G., Lavigne, R., Huys, I., Van den Mooter, G., Buckling, A., Debarbieux, L., Pouillot, F., Azeredo, J., Kutter, E., Dublanchet, A., Górski, A., Adamia, R., 2011. The phage therapy paradigm: Prêt-à-porter or sur-mesure? Pharm. Res. 28, 934-937.

Pirnay, J.P., Verbeken, G., Rose, T., Jennes, S., Zizi, M., Huys, I., Lavigne, R., Merabishvili, M., Vaneechoutte, M., Buckling, A., De Vos, D., 2012. Introducing yesterday's phage therapy in today's medicine. Future Virol. 7 (4), 379-390.

Smith, H.W., Huggins, M.B., 1982. Successful treatment of experimental Escherichia coli infections in mice using phage: its general superiority over antibiotics. J. Gen. Microbiol. 128, 307-318. 
Verbeken, G., De Vos, D., Vaneechoutte, M., Merabishvili, M., Zizi, M., Pirnay, J.P., 2007. European regulatory conundrum of phage therapy. Future Microbiol. 2, 485-491.

Weber-Dabrowska, B., Mulczyk, M., Górski, A., 2000. Bacteriophage therapy of bacterial infections: an update of our institute's experience. Arch. Immunol. Ther. Exp. 48, 547-551.

Wright, A., Hawkins, C.H., Anggård, E.E., Harper, D.R., 2009. A controlled clinical trial of a therapeutic bacteriophage preparation in chronic otitis due to antibiotic-resistant Pseudomonas aeruginosa; a preliminary report of efficacy. Clin. Otolaryngol. 34, 349-357.

Isabelle Huys*

Centre for Pharmaceutical Care and Pharmaco-Economy, Faculty of Pharmaceutical Sciences, Univ. Leuven, Leuven, Belgium
Mario Vaneechoutte

Laboratory Bacteriology Research (LBR),

Faculty of Medicine \& Health Sciences, Univ. Ghent, Belgium

Gilbert Verbeken

Burn Wound Centre, Queen Astrid Military Hospital,

Brussels, Belgium

Laurent Debarbieux

Department of Microbiology, Institut Pasteur, F-75015 Paris,

France

*Corresponding author. E-mail address: isabelle.huys@pharm.kuleuven.be 